\title{
Desarrollo de Comunicación Asertiva mediante el aprendizaje cooperativo en adolescentes Development of Assertive Communication through cooperative learning in adolescents
}

\author{
Joselin García Guzman ${ }^{1}$, Jessica Badillo Guzman ${ }^{2}$ \\ joselin.garcia.guzman.1994@gmail.com, jebadillo@uv.mx \\ ${ }^{1}$ Maestria en gestión del Aprendizaje \\ Universidad Veracruzana \\ ${ }^{2}$ Facultad de Pedagogía \\ Poza Rica, Ver., México \\ Universidad Veracruzana \\ Poza Rica, Ver., México
}

\begin{abstract}
Resumen-El presente trabajo describe las primeras fases de un proyecto de intervención en gestión del aprendizaje que se llevara a cabo en una institución educativa, el objetivo principal de este proyecto es implementar una estrategia de intervención fundamentada en el Aprendizaje Cooperativo que permita desarrollar la comunicación asertiva, la importancia de este proyecto radica, en la necesidad de crear un ambiente adecuado en el aula en donde los alumnos tengan confianza con sus compañeros y docentes, puedan resolver con éxito los conflictos, expresar sus opiniones y comentarios de manera adecuada. Se considera relevante la intervención en la institución con un taller de comunicación asertiva, pues éste impactaría en la transformación positiva de los alumnos, así como mejorar la relación y convivencia entre compañeros de clase.
\end{abstract}

Palabras clave: Aprendizaje Cooperativo, Comunicación Asertiva, Convivencia.

Abstract-The present work describes the first phases of an intervention project in learning management that will be carried out in an educational institution, the main objective of this project is to implement an intervention strategy based on Cooperative Learning that allows to develop assertive communication, The importance of this project lies in the need to create an adequate environment in the classroom where students have confidence with their peers and teachers, can successfully resolve conflicts, express their opinions and comments in an appropriate way. It is considered relevant the intervention in the institution with an assertive communication workshop, as this would impact on the positive transformation of students, as well as improving the relationship and coexistence among classmates.

\section{Keywords: Cooperative Learning, Assertive Communication,} Coexistence.

\section{INTRODUCCIÓN}

Es evidente que la comunicación es un aspecto central en el acto educativo, no sólo dentro del aula, sino también en nuestras relaciones interpersonales. A menudo, nos enfrentamos a dificultades a la hora de comunicarnos, o a la hora de resolver algunos conflictos, tanto en el aula como en nuestra vida cotidiana.
Se dice que para obtener un aprendizaje más inclusivo se deben de enseñar habilidades para la vida ya que estas favorecen el desarrollo de un proceso adecuado de enseñanzaaprendizaje.

Según la Organización Mundial de Salud (OMS) en 1993 propone 10 habilidades para la vida entre ellas la Comunicación Asertiva, entendiéndose la asertividad como una habilidad de comunicación interpersonal y social por medio de la cual el individuo es capaz de transmitir opiniones, intenciones, posturas, creencias y sentimientos con honestidad sin temor al rechazo, en un ámbito de respeto hacia uno mismo y hacia los demás.

La Asertividad desde otro punto de vista "Es la habilidad de exponer en un momento determinado (personal o social), de manera apropiada y directa, creencias y sensaciones tanto positivas como negativas. (Carrobles, 1979).

La persona que se comunica asertivamente expresa con claridad lo que piensa, siente o necesita, teniendo en cuenta los derechos, sentimientos y valores de sus interlocutores.

En palabras de Ortega (1997), “...en el centro educativo, la convivencia se entiende como el entramado de relaciones interpersonales que se dan entre todos los miembros de la comunidad educativa, y en el que se configuran procesos de comunicación, sentimientos, valores, actitudes, roles, status y poder".

Los procesos de enseñanza-aprendizaje se encuentran permeados por factores relacionados con el ámbito social, familiar, cultural, e individual que deben ser considerados en el momento de iniciar un proyecto de intervención.

La comunicación asertiva representa un factor decisivo para la convivencia social entre los seres humanos, en las instituciones escolares implica múltiples interacciones que abarcan la transmisión de ideas, opiniones e inquietudes; por lo que juega un papel muy importante para el establecimiento de una convivencia escolar sana y abierta para propiciar un proceso dialógico permanente entre alumnos, docentes $\mathrm{y}$ directivos. 


\section{CONTEXTO}

El presente trabajo de intervención en gestión del aprendizaje se realiza en una institución educativa de educación secundaria, el grupo a intervenir es el de segundo grado que consta de 32 alumnos, 18 hombres y 16 mujeres.

Después de un proceso de investigación y observación dentro de la institución y en particular en el grupo antes mencionado, los datos recabados nos indican la presencia de problemas relacionados con la comunicación y convivencia escolar, como lo son la falta de socialización entre compañeros, lenguaje ofensivo, agresiones de manera verbal, alumnos agresivos y alumnos pasivos.

La falta de asertivad, genera en el aula un clima desagradable, y una mala convivencia escolar, de acuerdo a los resultados obtenidos se formula la siguiente pregunta ¿Cómo desarrollar la comunicación asertiva a partir del aprendizaje cooperativo?

El objetivo General es implementar una estrategia de intervención fundamentada en el Aprendizaje Cooperativo que permita desarrollar la comunicación Asertiva.

Para atender esta problemática se propone el Aprendizaje Cooperativo entendido como "El uso instructivo de grupos pequeños para que los estudiantes trabajen juntos y aprovechen al máximo el aprendizaje propio y el que se produce en la interrelación. Para lograr esta meta, se requiere planeación, habilidades y conocimiento de los efectos de la dinámica de grupo". (Johnson \& Johnson, 1991)

Las consecuencias que trae la falta de comunicación en el proceso áulico, repercute directamente en todas las asignaturas, por lo tanto es primordial darle solución a esta necesidad para avanzar en la sana convivencia de los estudiantes.

La importancia de este proyecto radica, entonces, en la necesidad de crear un ambiente adecuado en el aula en donde los alumnos tengan confianza con sus compañeros y docentes, puedan resolver con éxito los conflictos y comunicarse con sinceridad, tanto para expresar sus opiniones como para exponer sus inseguridades y comentarios.

La relevancia de generar un proyecto de intervención en la institución enfocado a la comunicación asertiva radica en el impacto que éste tendría en la transformación positiva de los alumnos, así como mejorar la relación y convivencia entre compañeros de clase.

La temática de comunicación asertiva en el aula no se ha trabajado, existe en formación cívica y ética un módulo en donde se habla de resolución de conflictos pero la materia no es vista de manera recurrente, se da más peso a español y matemáticas.

\section{DESCRIPCIÓN}

La metodología a utilizar en este proyecto es la investigación-acción, desde esta metodología, la Maestría en gestión del aprendizaje ha definido cinco fases para gestionar aprendizajes en el aula:

La primera es el Diseño del proyecto de intervención que crea las condiciones para intervenir, aquí se realiza el primer acercamiento a la institución educativa y el diagnóstico. La segunda es la Planeación, donde se diseña y se formulan los objetivos del plan de mejora a realizar. La tercera es la implementación y acción, que permite el proceso de intervención desarrollando mecanismos de seguimiento, revisión y evaluación de los aprendizajes esperados. La cuarta es la Evaluación de la intervención en general, la cual permite valorar íntegramente todo el proceso de intervención y la última fase es la culturización y difusión que permite incorporar y compartir toda la dinámica organizativa de los procesos establecidos, en donde además se puede socializar el proyecto para fortalecer la intervención. (Pérez L, 2016).

La metodología de investigación-acción consiste en profundizar la comprensión del profesor (diagnóstico) de su problema. Por tanto, adopta una postura exploratoria frente a cualesquiera definiciones iniciales de su propia situación que el profesor pueda mantener (Elliot, J. 2000).

En la primera fase del proyecto de intervención se realizó la etapa de crear las condiciones para intervenir, aquí se inicia un primer acercamiento a la institución educativa, la etapa consta en primera instancia de tener el contacto con el director de la escuela, para conocer la importancia y finalidad de llevar a cabo un proyecto de intervención para enriquecer el aprendizaje de los alumnos, el director de la institución otorgó el permiso para realizar un proyecto de intervención.

Conformadas las fechas, se realizó una entrevista al director, donde se trabajó con una guía de entrevista para conocer aspectos del contexto interno tales como son: datos generales de la institución, visión, infraestructura, equipamiento, normas, plantilla docente, matricula, clima de la institución así como la forma de organización del trabajo escolar.

Después de conformar el contexto interno se prosiguió con una búsqueda de información para documentarse sobre el contexto externo, investigar sobre los planes y programas desde los cuales se apoya el modelo de telesecundarias en México, así como el panorama y políticas regionales, nacionales e internacionales desde las cuales se apoya la educación básica.

Se hizo un análisis del contexto interno y externo en el que se plasmaron aspectos que servirían como soporte para valorar los riesgos, costos y oportunidades de crear un proyecto de gestión de aprendizaje, teniendo como fortalezas la disposición y aceptación del director de la escuela, así como la motivación de los profesores de grupo , algunos de los obstáculos que se encontraron presentes para llevar a el proyecto de intervención, fueron la poca participación de los padres de familia en la educación de los alumnos, algunas conductas antisociales mencionadas por el director, así como el bajo rendimiento escolar.

Para la Detección de necesidades, se realizó un primer acercamiento con el grupo a intervenir, se plantearon los tiempos y negociación con el director y la maestra de grupo, se realizó la recuperación de la información del grupo por medio de la observación, se elaboró una guía de observación que consto de 15 categorías de análisis las cuales fueron: Ambiente en aula, planeación, temáticas desarrolladas, metodología de enseñanza, metodología de aprendizaje, participación de estudiantes, problemáticas o necesidades, áreas de oportunidad detectadas, recursos del aula, recursos utilizados en clase, formas de evaluación, tareas, interés y motivación de los estudiantes, interés y motivación del profesor y los eventos significativos en clase. 
Para culminar con esta fase se hace un diagnóstico a partir de la necesidad detectada, aplicando tres instrumentos los cuales son: Cuestionario de asertividad, Cuestionario de tipos de comportamiento y una ficha biográfica.

El cuestionario de asertividad se conformó de 10 preguntas las cuales recuperaron aspectos de interacción de los alumnos, así como si son asertivos o no asertivos, la validez del instrumento se comprobó una vez aplicados los cuestionarios, para el procesamiento de la información se vaciaron las respuestas en una tabla, la cual tenía las respuestas asertivas y las no asertivas, al final el número de respuestas daba una puntación, con la cual se tomaba en asertivo o no asertivo.

La ficha biográfica recupero aspectos personales de los alumnos, tales como edad, dirección, número de integrantes de la familia, aspectos que recuperaron datos de la dinámica familiar, así como de interacción con los integrantes de la familia, tanto de la manera en que se comunican con sus padres y como se desenvuelven en su entorno, para el procesamiento de la información se anotaron los aspectos más importantes presentes entre los alumnos.

El Cuestionario de estilos de comportamiento se conformó por 13 preguntas las cuales recuperaron características de los diferentes tipos de comportamiento, ya sea asertivo, pasivo, o agresivo, al final para el procesamiento de la información se vaciaron las respuestas de cada uno de los alumnos en un programa de Microsoft llamado Exel , que dio como resultado el porcentaje total de los alumnos en cada comportamiento, para así tener en cuenta el comportamiento más imperante dentro del salón de clases.

A partir de lo anterior, nos encontramos trabajando en la planeación de la implementación de la estrategia para la gestión del aprendizaje. Hasta ahora, es pertinente utilizar la estrategia de aprendizaje cooperativo ya que esta permitirá la interacción de los alumnos cara a cara, además de trabajar las habilidades sociales y de convivencia escolar.

Para la fase de Planeación se está considerando de entrada, crear un curso- taller que tenga por objetivo conocer e incorporar las herramientas de comunicación asertiva mediante el aprendizaje cooperativo con el fin de optimizar las relaciones interpersonales, que los alumnos puedan expresarse de manera asertiva en su vida escolar y cotidiana.

Dentro de las actividades, se considera importante incluir el video digital y algunos recursos multimedia que permitan captar la atención de los alumnos. El uso del video en el salón de clases facilitaría la construcción del conocimiento significativo dado que se aprovecharía el potencial comunicativo de las imágenes, los sonidos y las palabras para transmitir una serie de experiencias que estimulen los sentidos y los distintos estilos de aprendizaje de los alumnos.

\section{Resultados}

En este apartado presentamos los resultados obtenidos después de la detección de necesidades en el salón de clases, resultados de un diagnostico que permitió conocer aspectos enfocados a la comunicación, interacción y trabajo en equipo que permitirán el diseño de un plan de acción para el desarrollo de la comunicación asertiva a través del aprendizaje cooperativo.
Partiendo como primera instancia de la detección de necesidades se encontró la necesidad de incorporar competencias comunicativas ya que los alumnos no saben expresarse de manera clara, no respetan la participación de otros compañeros tornándose en comentarios hirientes o lenguaje ofensivo, se presentaron incidentemente problemas que van relacionados a la comunicación los cuales son; agresiones de manera verbal, lenguaje ofensivo, falta de socialización entre compañeros, maneras de contestar inadecuadas ante los cuestionamientos de la profesora, alumnos agresivos y pasivos, se consideró pertinente la realización de un proyecto de intervención enfocado a los problemas de comunicación que hay dentro del aula ya que esto permitirá una mejor convivencia escolar.

La importancia de generar un proyecto de comunicación asertiva radica, entonces, en la necesidad de crear un ambiente adecuado en el aula en donde los alumnos tengan confianza con sus compañeros y docentes, puedan resolver con éxito los conflictos y comunicarse con sinceridad, tanto para expresar sus opiniones como para exponer sus inseguridades y comentarios.

Para la realización del diagnóstico, se utilizaron los siguientes instrumentos:
A. Cuestionario de Asertividad
B. Ficha Biográfica
C. Cuestionario De Estilos de Comportamiento.

Enseguida se presentan los resultados obtenidos en cada uno de ellos:

\section{A) Cuestionario de Asertividad}

Resultados: Durante una conversación los alumnos no se dan cuenta de sus propias debilidades, además de que les cuesta ver sus fortalezas, a la hora de comunicarse con sus demás compañeros tienen una tendencia a culpar a los demás por sus errores, defienden sus opiniones al hablar con otras personas, pero siempre de manera agresiva, hiriendo los sentimientos y la susceptibilidad de la otra persona. Tienen en mente que el trabajo en equipo no les permite realizar mejor sus tareas escolares, no se apoyan entre compañeros, el trato que se dan se vuelve irrespetuoso ya que no respetan las opiniones de sus demás compañeros, lo que da como resultado una conducta no asertiva.

\section{B) Ficha Biográfica}

Resultados: Los alumnos oscilan entre las edades de 12 a 14 años, tienen familias conformadas por 4 a 6 integrantes, los padres de familia se dedican al trabajo en el comercio informal, viven en un ambiente que nos les permite desenvolverse de la manera adecuada ya que los padres trabajan prácticamente todo el día, los problemas familiares los resuelven a base de gritos, todos manifiestan una mala comunicación con los integrantes de su familia, la comunicación se ve afectada por los distintos factores familiares, tanto de los padres hacia los hijos como de los hijos hacia los padres.

\section{C) Cuestionario de estilos de comportamiento}

Resultados: Arrojan que son el $66 \%$ de los alumnos son agresivos, 33\% pasivos y 3\% asertivos, lo cual fundamenta las observaciones en aula, además de que les cuesta mucho trabajar en equipo, aceptar las opiniones de las demás 
personas, tienen una convivencia que no es sana en su contexto familiar, lo que se ve reflejado en su comportamiento en el aula.

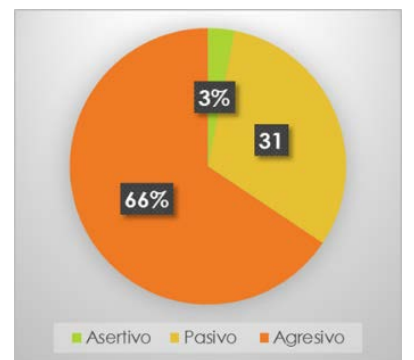

Figura1. Resultados Globales de Cuestionario de estilos de comportamiento

La mayoría de los alumnos mantiene un comportamiento agresivo, en donde estos alumnos no respetan las opiniones de los demás, piensan que mientras más débiles sean los demás, más fuertes serán ellos, se alimentan de conductas pasivas para redefinir su carácter agresivo, tienen un menosprecio a los demás, en cuento a los demás resultados algunos de los alumnos mantienen un comportamiento pasivo lo que quiere decir que estos alumnos anteponen sus opiniones y deseos por los demás, siempre quieren agradar a las demás personas aunque estén violentando sus derechos.

Haciendo una comparación entre los tres instrumentos aplicados para la realización del diagnóstico, podemos darnos cuenta de la mala comunicación que existe en el contexto familiar y escolar de los alumnos, por lo tanto la mayoría se enfrasca en el comportamiento agresivo, lo que refleja toda esa mala comunicación y por consiguiente el comportamiento no asertivo.

\section{CONCLUSIONES}

La comunicación asertiva tiene un papel importante para que los alumnos se sitúen en un punto medio entre otras dos conductas polares: la agresividad y la pasividad, con la puesta en marcha de un taller de comunicación asertiva los alumnos tendrán los conocimientos teóricos y prácticos de esta conducta, con ello podrán mejorar su relaciones a nivel personal pero también a nivel escolar, mejorando con esto la convivencia escolar.

Trabajar la asertividad, favorece la gestión del aprendizaje entre los estudiantes, el tener una buena convivencia escolar ayuda a mejorar el rendimiento académico, esto funge como un elemento que favorecedor para una incidencia positiva en el aprendizaje.

El trabajar desde el aprendizaje cooperativo permitirá la interacción de los estudiantes, esto será cara a cara, los alumnos obtendrán resultados que serán beneficiosos para ellos mismos y para todos sus compañeros, además de maximizar su propio aprendizaje y el de los demás.
Debe contener la sostenibilidad del trabajo, la transferibilidad a otros contextos y las recomendaciones de aplicación.

\section{REFERENCIAS}

Carrobles Costa Del Sur, B. (1979). La práctica en la terapia de la conducta: teoría y métodos de aplicación para la práctica clínica. Madrid: Pablo del Río.

Elliot, J. (2000). La investigación-acción en educación. Ediciones Morata S.L, cuarta edición.

Jonson, D. Y Jonson, R. (1991). Learning together and alone. Cooperative, competitive and individualistic learning. Needham Heights, Allyn and Bacon.

Ortega, R. (1997). “El proyecto Sevilla Anti-violencia Escolar. Un modelo de intervención preventiva contra los malos tratos entre iguales". Revista de Educación, 313, 143- 158.

Pérez, L. I. S. M., Villanueva, R. H., Vences, M. P., \& Casanova, E. M. M. (2016). La metodología APRA una alternativa para intervenir en contextos educativos vulnerables. Revista Iberoamericana de Producción Académica y Gestión Educativa.

Schank, R. C. (2002). Every curriculum tells a story. International Journal of Cognition and Technology, 1(1), pp. 169-182. 